\title{
Propagação do ‘Boysenberry’ por estaquia e mergulhia
}

\author{
'Boysenberry' propagation by cutting and layering
}

\author{
Andrei Spaziani Tiberti ${ }^{\mathrm{I}}$ Rafael Pio $^{\mathrm{I}^{*}}$ Cynthia Natally de Assis ${ }^{\mathrm{I}}$ Kelly Nascimento Silva ${ }^{\mathrm{I}}$ \\ Maraisa Hellen Tadeu ${ }^{\mathrm{I}}$
}

\section{RESUMO}

Visando a estudar a propagação por estaquia $e$ mergulhia do 'Boysenberry' (híbrido entre 'Marionberry' $e$ framboesa), o objetivo do presente trabalho foi quantificar o potencial rizogênico de estacas caulinares armazenadas a frioúmido e tratadas com ácido indolbutírico e da mergulhia desse híbrido. No primeiro experimento, estacas caulinares de $15 \mathrm{~cm}$ foram tratadas com diferentes concentrações de ácido indolbutírico (AIB): 1000, 2000, 3000 e 4000mg L-1 por 10seg., além do controle composto somente por água. No segundo experimento, as estacas foram armazenadas a frio-úmido por $10,20,30,40,50$ e 60 dias, além do controle sem armazenamento. Em ambos os experimentos, as estacas caulinares foram enterradas $2 / 3$ de seu comprimento na posição vertical, utilizando a vermiculita de grânulos finos como substrato, em telado com sombreamento de 50\%. Após 60 dias, foram analisadas as porcentagens de enraizamento, brotação e o número médio de raízes. No terceiro experimento, as mergulhias de ponta foram realizadas na porção apical dos ramos, aplicando-se, na extremidade do ramo, diferentes concentrações de AIB (0, 1000, 2000, 3000 e 4000mg L $\left.{ }^{-1}\right)$. Os ramos foram enterrados em caixas de plástico contendo o substrato casca de pinus umedecido. Passados 45 dias, foram removidos para a mensuração. Concluiu-se que as estacas caulinares devem ser armazenadas a frio-úmido por 20 dias $e$ não serem tratadas com AIB; a mergulhia de ponta promoveu maior emissão de raízes quando tratadas com $4000 \mathrm{mg} \mathrm{L}^{-1}$.

Palavras-chave: produção de mudas, ácido indolbutirico, armazenamento a frio.

\section{ABSTRACT}

In order to study the propagation by cutting and layering by 'Boysenberry' (hybrid between 'Marionberry'e framboesa), the objective of the present study was to quantify the rizogenic potential of stems cuttings storage at cold temperature and treated with indolbutyric acid and the point layering of this hybrid. In the first experiment, the stems cuttings of $15 \mathrm{~cm}$ of length were treated with different concentrations of indolbutyric acid (IBA): 1000, 2000, 3000 and 4000mg $\mathrm{L}^{-1}$ for 10 seconds, and control only for water. In the second experiment, the stems cuttings of 'Boysenberry' were cold storage by 10 , 20, 30, 40, 50 and 60 days, and control without storage. In both experiments, the stems cuttings were buried $2 / 3$ of its length in the vertical position, using the vermiculita as substrate, in greenhouse with 50\% of light. After 60 days, the rooting and sprouting percentage and the number of roots were evaluated. In the third experiment, the point layering were accomplished in the apical portion of the branches, being applied different concentrations of IBA $\left(0,1000,2000,3000\right.$ and $\left.4000 \mathrm{mg} \mathrm{L}^{-1}\right)$ and soon after, they were buried in plastic boxes containing humidified pinus substrate. After 45 days they were removed for evaluation. It can be concluded that the stems cuttings should be stored at cold for 20 days and without IBA; the point layering promoted larger emission of roots when they were treated with $4000 \mathrm{mg} \mathrm{L}^{-1}$.

Key words: seedlings production, indolbutyric acid, cold storage.

\section{INTRODUÇÃO}

O consumo de amoras-pretas (Rubus spp.) e framboesas (Rubus idaeus) vem aumentando paulatinamente nos últimos anos, devido às características intrínsecas de suas frutas, consideradas como fonte natural em antioxidantes e pigmentos, úteis na prevenção de doenças degenerativas e cancerígenas

IDepartamento de Agricultura, Universidade Federal de Lavras (UFLA), CP 3037, 37200-00, Lavras, MG, Brasil. E-mail: rafaelpio@dag.ufla.br.*Autor para correspondência. 
(FERREIRA et al., 2010). Além das amoras-pretas e framboesas, existem outras frutíferas do gênero Rubus que possuem frutas com características químicas e produtivas similares, como o ‘Boysenberry', um híbrido entre o 'Marionberry' (Rubus ursinus) e a framboesa vermelha.

Existem plantações comerciais de ‘Boysenberry’ em Oregon e na Califórnia, nos Estados Unidos, na Nova Zelândia e mais recentemente no Chile (HALL \& LANGFORD, 2008), além de alguns pequenos pomares localizados em Campos do Jordão-SP, destinados ao turismo rural e à confecção de geléias e sucos, comercializados no próprio município. Apesar da recente exploração comercial do ‘Boysenberry’, há carência de informações fitotécnicas sobre seu cultivo, principalmente no que se refere ao processo de produção de mudas, uma vez que não há relatos sobre as formas de propagação por estaquia ou mergulhia.

No caso da amora-preta, a propagação é realizada através de estacas caulinares. São coletados fragmentos dos ramos no período hibernal ou na poda de verão e posteriormente removidas as folhas e confeccionadas as estacas (ANTUNES et al., 2000). Algumas técnicas têm sido utilizadas visando a potencializar a emissão de raízes na propagação por estacas. Uma delas é a utilização do ácido indolbutírico (AIB), uma auxina foto-estável e que vem sendo usualmente empregada no enraizamento de espécies que possuem baixa capacidade rizogênica (HAN et al., 2009). Outra técnica é o armazenamento das estacas em baixas temperaturas, que consiste em expor as estacas em temperaturas reduzidas e à ausência de luz (estiolamento). O armazenamento auxilia na superação da endodormência das gemas e propicia aumento da emissão de brotações nas estacas (SALIBE et al., 2010). Por sua vez, o estiolamento contribui para induzir a inibição do sistema enzimático AIA-oxidase, aumentando assim a ação da auxina natural AIA nas estacas (BIASI, 1996).

Já a mergulhia, outra técnica de propagação vegetativa, concilia o enraizamento de uma porção do ramo ainda conectado à planta-matriz, melhorando as condições para que a rizogênese aconteça. Pode ser empregada a mergulhia subterrânea ou a mergulhia aérea, conhecida também como alporquia. A propagação pelo método de mergulhia apresenta vantagens em relação à estaquia, dentre as quais estão $o$ alto percentual de enraizamento e a independência de infraestrutura (casa de vegetação com sistema de nebulização), sendo essa uma alternativa potencial no enraizamento (DANELUZ et al., 2009).

Visando a aperfeiçoar o processo de produção de mudas clonais do ‘Boysenberry’ em larga escala comercial, o referido trabalho teve como objetivo verificar o potencial de enraizamento de estacas caulinares tratadas com AIB e armazenadas a frioúmido, bem como a mergulhia.

\section{MATERIAL E MÉTODOS}

Foram realizados três experimentos entre os meses de abril de 2010 a março de 2011, no Setor de Fruticultura da Universidade Federal de Lavras (UFLA), Lavras-MG. As plantas matrizes de 'Boysenberry' foram levadas a campo em novembro de 2009, com altura média de $60 \mathrm{~cm}$ e bem ramificadas.

Nos experimentos de enraizamento, as estacas caulinares semilenhosas foram coletadas nas plantas matrizes no mês de abril e foram padronizadas com $15 \mathrm{~cm}$ de comprimento e diâmetro ao redor de $8 \mathrm{~mm}$, sendo removidas as folhas e efetuado um corte reto no ápice da estaca e outro em bisel na base, conforme as recomendações de ANTUNES et al. (2000). No primeiro experimento, as estacas foram tratadas com diferentes concentrações de AIB: 1000, 2000, 3000 e 4000 $\mathrm{mg} \mathrm{L}^{-1}$ por 10seg., além do controle composto somente por água.

No segundo experimento, as estacas foram separadas em feixes de 40 estacas e posteriormente embrulhadas em jornal umedecido, colocadas dentro de sacos plásticos vedados e armazenadas em geladeira (temperatura próxima a $4^{\circ} \mathrm{C}$ - armazenamento a frioúmido) por diferentes períodos: 10, 20, 30, 40, 50 e 60 dias, segundo as recomendações de CELANT et al. (2010). Como controle, foi utilizada uma quantidade de estacas sem passar pelo processo de armazenamento.

Em ambos os experimentos, as estacas caulinares foram enterradas $2 / 3$ de seu comprimento na posição vertical, em caixas plásticas preenchidas com vermiculita de grânulos finos, localizadas dentro de telado com sombreamento de $50 \%$. O delineamento utilizado foi o inteiramente casualizado, sendo o primeiro experimento composto por cinco tratamentos (concentrações de AIB) e o segundo experimento por sete tratamentos (períodos de armazenamento). Os experimentos foram compostos por quatro repetições e dez estacas por unidade experimental. As estacas foram diariamente umedecidas e, ao final de 60 dias após o estaqueamento, foram mensuradas as porcentagens de estacas enraizadas, brotadas e o número médio de raízes.

Já no terceiro experimento, foram realizadas mergulhias de ponta em ramos semilenhosos do 'Boysenberry' no mês de janeiro. Foram realizados cortes em bisel na porção apical dos ramos, sendo removidas as brotações e folhas laterais. Posteriormente à realização dos cortes, foram aplicadas diferentes concentrações de AIB: 1000, 2000, 3000 e $4000 \mathrm{mg} \mathrm{L}^{-1}$, além do controle composto somente por 
água, com auxílio de um pincel de cerdas finas. Enterrouse $15 \mathrm{~cm}$ da extremidade dos ramos em caixas plásticas preenchidas com substrato a base de casca de pinus, que foram diariamente umedecidas. $\mathrm{O}$ delineamento utilizado foi o inteiramente casualizado, com cinco tratamentos (concentrações de AIB), com quatro repetições e dez mergulhias por unidade experimental. Ao final de 45 dias, foram mensuradas as porcentagens ramos enraizados, brotados e o número médio de raízes.

Os dados foram submetidos à análise de variância e as médias submetidas à análise de regressão, em nível de 5\% de probabilidade.

\section{RESULTADOS E DISCUSSÃO}

No primeiro experimento, verificou-se que a maior porcentagem de estacas enraizadas (88\%) e brotadas (78\%) foi obtida sem o tratamento com AIB (Figura 1A). Ocorreu decréscimo linear da porcentagem de brotação, enraizamento e do número médio de raízes, conforme se submeteu as estacas de 'Boysenberry' nas concentrações crescentes da referida auxina sintética, chegando a se obter apenas $16 \%$ de estacas enraizadas e nenhuma estaca brotada quando se tratou as estacas com a solução de $4000 \mathrm{mg} \mathrm{L}^{-1}$ de AIB. Para o número médio de raízes, a ausência do tratamento com AIB propiciou a emissão de 13,08 raízes e apenas 4,28 raízes quando se utilizou $4000 \mathrm{mg} \mathrm{L}^{-1}$ de AIB, decréscimo de 8,8 raízes em relação ao controle (Figura 1B).

Nesse sentido, pressupõe-se que os níveis hormonais endógenos nos ramos das plantas matrizes de 'Boysenberry' estavam em quantidades adequadas a fim de estimular a emissão de raízes na época em que as estacas foram coletadas (mês de abril). Segundo LJUNG et al. (2001) e HAN et al. (2009), as auxinas naturais que auxiliam na emissão de raízes são sintetizadas nas gemas e folhas tenras, sendo posteriormente translocadas para o local de ação. Dependendo do nível hormonal endógeno, a suplementação com auxinas sintéticas, a exemplo do AIB, pode desbalancear os níveis hormonais e desfavorecer o enraizamento.

Esses resultados estão de acordo com os encontrados por VILLA et al. (2003), que, trabalhando com o enraizamento de estacas caulinares da amoreirapreta 'Brazos', pertencente ao mesmo gênero do 'Boysenberry' (Rubus), constataram que o tratamento com AIB desfavoreceu o enraizamento das estacas. O mesmo caso foi registrado por ANTUNES et al. (2000), que evidenciaram que as estacas caulinares de amoreira-preta não precisam ser tratadas com auxina sintética. Esses resultados são interessantes, uma vez que o processo de produção de mudas do 'Boysenberry' por estacas caulinares fica mais simples.

No segundo experimento, as estacas de ‘Boysenberry’ que não passaram pelo armazenamento a frio-úmido registraram $71,15 \%$ de enraizamento e as estacas que foram armazenadas por 20 dias apresentaram 89\%, acréscimo de 17,84\% em relação ao controle (Figura 2A). Quanto à brotação, as estacas que foram armazenadas por 17 dias apresentaram 80,35\% de porcentagem de brotação, 12,41\% a mais em relação às estacas que não foram armazenadas a frioúmido (Figura 2A). O mesmo fato ocorreu na emissão das raízes nas estacas, em que o armazenamento a frioúmido por 25 dias praticamente estimulou o aumento de $50 \%$ na emissão de raízes, obtendo-se 18,5 raízes, 9,32 a mais em relação às estacas que não foram armazenadas (Figura 2B).

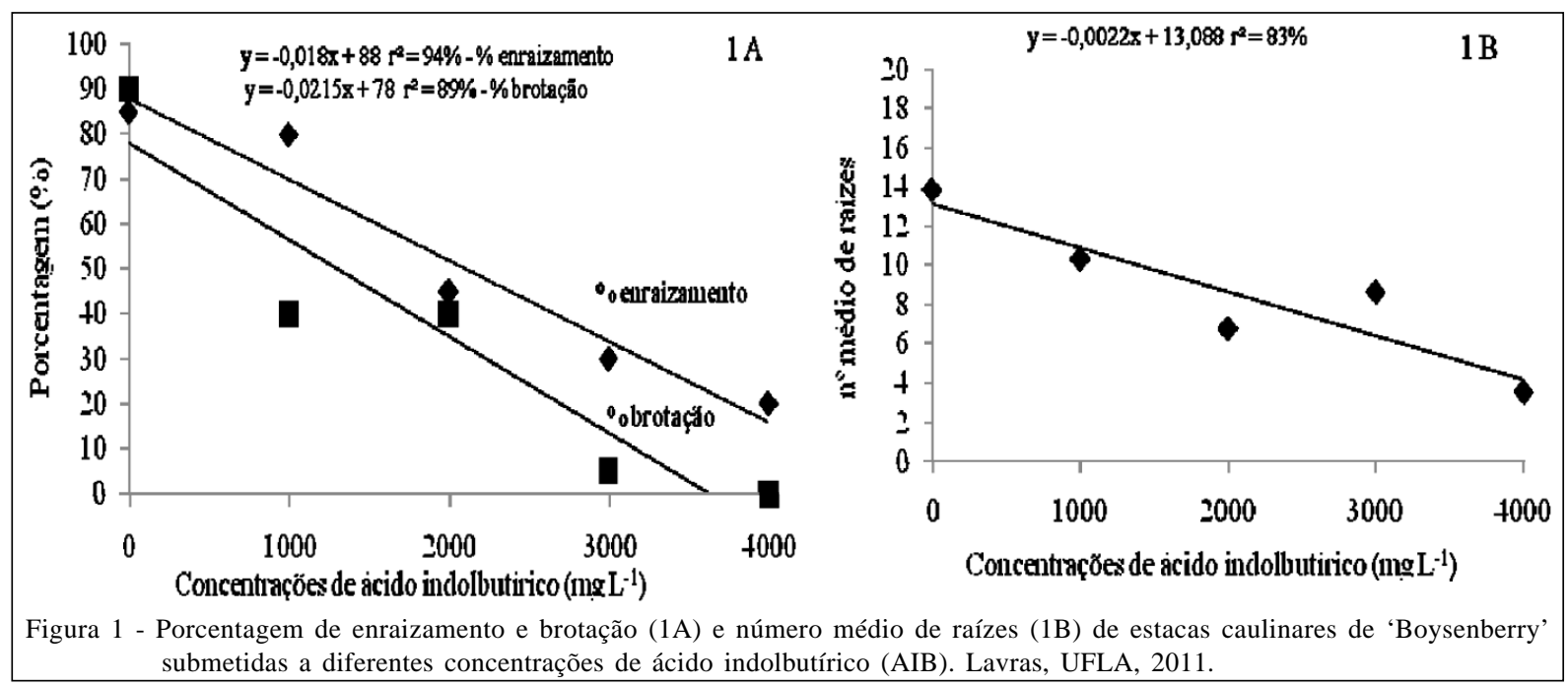

Ciência Rural, v.42, n.3, mar, 2012. 

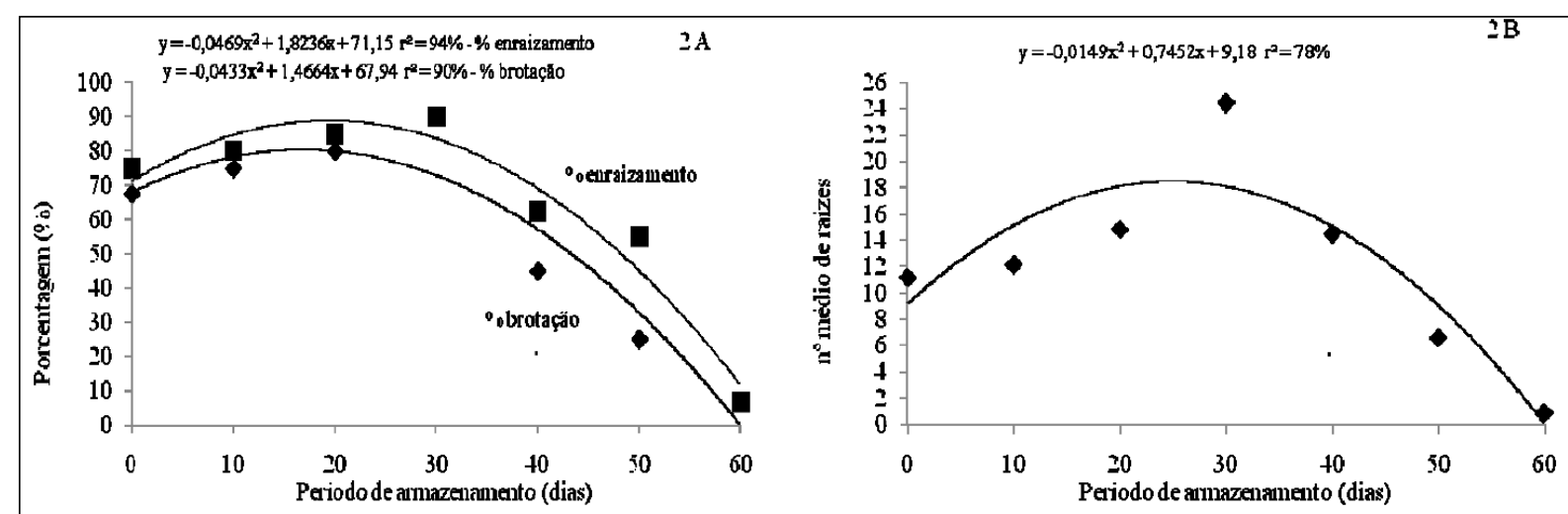

Figura 2 - Porcentagem de enraizamento e brotação (2A) e número médio de raízes (2B) de estacas caulinares de 'Boysenberry' armazenadas a frio-úmido por diferentes períodos. Lavras, UFLA, 2011.

Percebe-se que houve estímulo das baixas temperaturas na melhoria do potencial rizogênico e brotação das estacas de 'Boysenberry'. Segundo PIO et al. (2007), o armazenamento em baixas temperaturas tem como intuito superar a endodormência das gemas das estacas e aumentar a emissão de brotações, uma vez que as frutíferas de clima temperado necessitam da exposição em baixas temperaturas para que ocorra estímulo à brotação. $\mathrm{O}$ armazenamento em baixas temperaturas ainda contribui para o aumento da emissão das raízes, pois o estiolamento das estacas aumenta a presença de compostos fenólicos, como o ácido clorogênico, floroglucinol, ácido caféico e catecol, inibidores da síntese da AIA-oxidase, aumentando assim a ação da auxina natural AIA nas estacas (BIASI, 1996). Mas é importante salientar que esses níveis hormonais endógenos possivelmente atingiram uma concentração que não exigiu a necessidade da aplicação exógena do AIB, conforme relatado no primeiro experimento.
Segundo CÉLINE et al. (2006), a capacidade dos fragmento de genótipos elite em emitirem raízes pode estar relacionada à espécie ou ainda ao método de propagação. Assim, em alguns casos, é necessária a suplementação com auxinas exógenas para se aumentar a emissão de raízes (HAN et al., 2009). Percebe-se que, no caso do 'Boysenberry', a necessidade em se utilizar auxina sintética a fim de estimular a emissão de raízes e o aumento da porcentagem de enraizamento e brotação está relacionada com o método de propagação, já que os experimentos com estacas demonstraram que não houve necessidade da utilização de AIB e, quando se aplicou, ocorreu decréscimo do potencial rizogênico. O mesmo resultado não ocorreu para a propagação por mergulhia, pois, no terceiro experimento, houve influência da aplicação do AIB na melhoria do enraizamento nos ramos que foram mergulhados. A aplicação da solução de $4000 \mathrm{mg} \mathrm{L}^{-1}$ de AIB estimulou o enraizamento de $98,4 \%$ de estacas, $14,4 \%$ a mais em relação ao controle (Figura 3A). Essa mesma
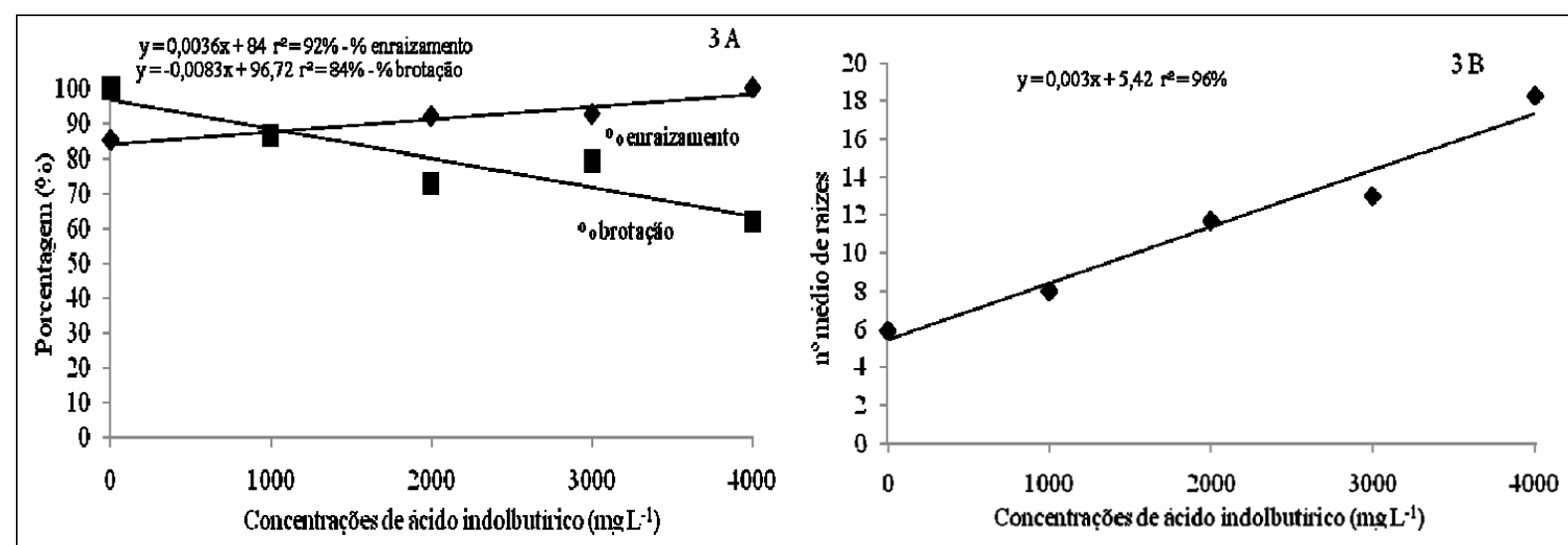

Figura 3 - Porcentagem de enraizamento e brotação (3A) e número médio de raízes (3B) de ramos do 'Boysenberry' tratados com diferentes concentrações de ácido indolbutírico (AIB) e submetidos ao enraizamento por mergulhia de ponta. Lavras, UFLA, 2011. 
concentração ainda estimulou a emissão de 17,42 raízes, 12 raízes a mais em relação ao controle (Figura 3B). Esses resultados concordam com DANELUZ et al. (2009), que mencionaram a necessidade da aplicação de AIB para a melhoria da emissão de raízes no processo de produção de mudas de figueira por mergulhia aérea.

Porém, o não tratamento com AIB estimulou a emissão de brotações em 96,72\% das estacas, 33,2\% a mais em relação aos ramos que foram tratados com 4000 $\mathrm{mg} \mathrm{L}^{-1}$ de AIB (Figura 3A).

Essa divergência quanto à necessidade em se utilizar o AIB com relação ao processo de multiplicação do ‘Boysenberry’ por estacas caulinares e mergulhia pode estar relacionada ao método de propagação. Segundo LJUNG et al. (2001), as auxinas são sintetizadas em gemas e folhas tenras e posteriormente são transportadas para o local de ação. Como a mergulhia foi realizada na porção apical dos ramos e as folhas tenras se localizam na porção basal dos ramos, acredita-se que a extremidade dos ramos continha menor concentração endógena de auxina e foi requerida suplementação com concentrações elevadas de AIB.
Diante dos excelentes resultados de enraizamento e emissão de raízes obtidas pelo presente trabalho, o processo de multiplicação vegetativa do 'Boysenberry' por estaquia e mergulhia de ponta apresenta-se como técnica promissora para obtenção de mudas dessa espécie. Na figura 4, pode-se observar o potencial rizogênico e a qualidade das raízes dos propágulos. Vale ressaltar a importância das estacas conterem grande volume de raízes, o que será fundamental no desenvolvimento da mudas após o plantio, podendo ainda refletir positivamente no desempenho produtivo inicial das plantas

\section{CONCLUSÃO}

O 'Boysenberry' pode ser propagado por estacas caulinares e por mergulhia. As estacas não devem ser tratadas com AIB, mas sim armazenadas a frio-úmido por 20 dias. A mergulhia promoveu maior emissão de raízes quando tratadas com 4000mg L-1 de ácido indolbutírico.

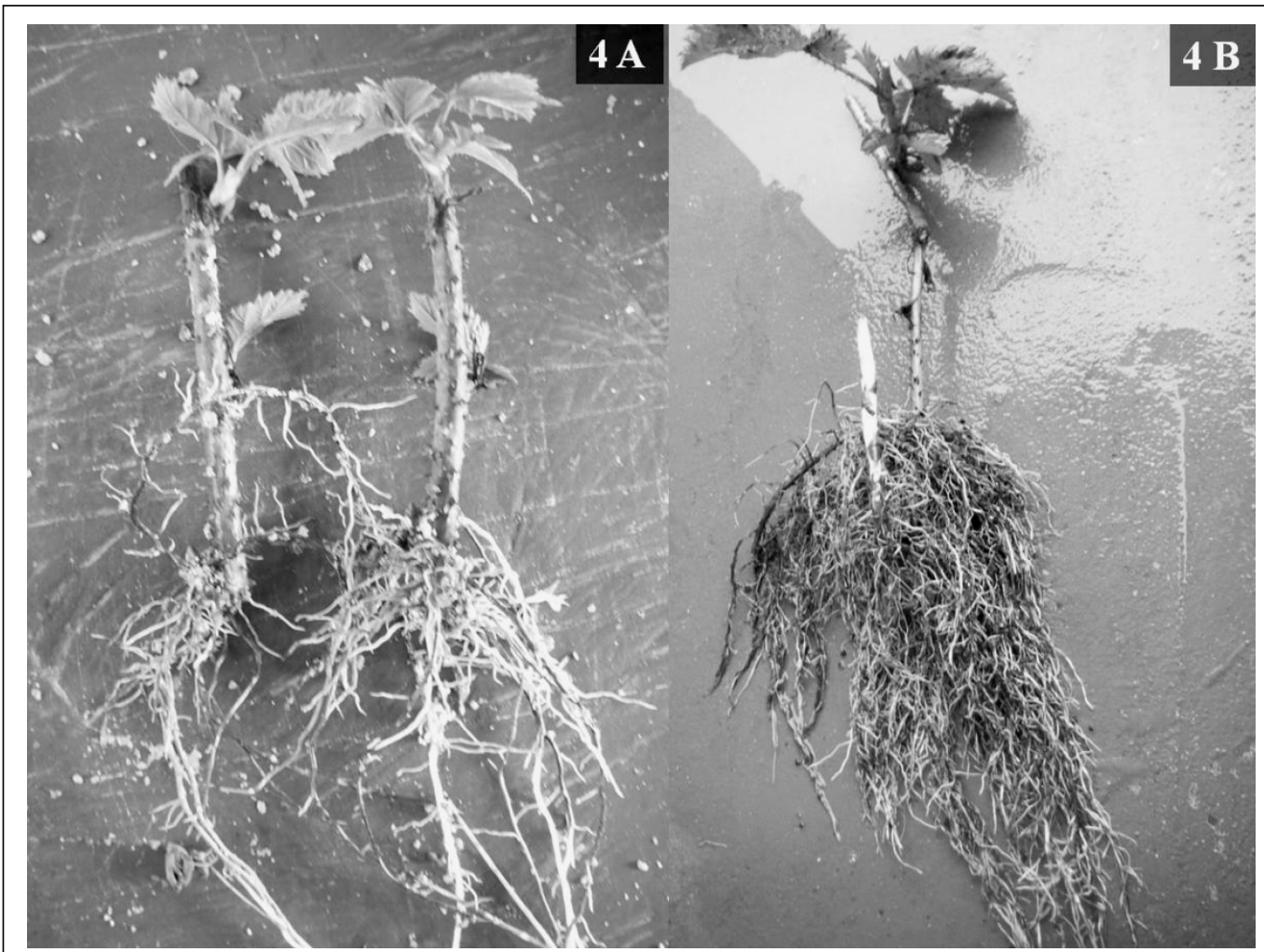

Figura 4 - Sistema radicular formado em estacas de 'Boysenberry' enraizadas por estaquia sem o tratamento com AIB (4A) e por mergulhia de ponta em ramos tratados com 4000 $\mathrm{mg} \mathrm{L}^{-1}$ de AIB (4B). Lavras, UFLA, 2011. 


\section{REFERÊNCIAS}

ANTUNES, L.E.C. et al. Propagação de cultivares de amoreirapreta (Rubus spp.) através de estacas lenhosas. Revista Brasileira de Fruticultura, v.22, n.2, p.195-199, 2000.

BIASI, L.A. Emprego do estiolamento da propagação de plantas. Ciência Rural, v.26, n.2, p.309-314, 1996. Disponível em: <http://www.scielo.br/scielo.php?pid=S010384781996000200025\&script=sci_arttext $>$. Acesso em: 29 abr. 2011. doi: 10.1590/S0103-84781996000200025.

CELANT, V.M. et al. Armazenamento a frio de ramos portaborbulhas e métodos de enxertia de cultivares de marmeleiro. Ciência Rural, v.40, n.1, p.20-24, 2010. Disponível em: <http:/ /www.scielo.br/scielo.php?script=sci_arttext\&pid=S010384782010000100004\&lng=pt\&nrm=iso $>$. Acesso em: 11 mar. 2011. doi: 10.1590/S0103-84782009005000223.

CÉLINE, S. et al. Proteomic analysis of different mutant genotypes of arabidopsis led to the identification of 11proteins correlating with adventitious root development. Plant Physiology, v.140, n.1, p.349-364, 2006.

DANELUZ, S. et al. Propagação da figueira 'Roxo-de-Valinhos' por alporquia. Revista Brasileira de Fruticultura, v.31, n.1, p.285-290, 2009. Disponível em: <http://www.scielo.br/ scielo.php? s c ri pt t=s ci_art text \& pid=S $0100-$ 29452009000100041\&lng=pt\&nrm=iso\&tlng=pt $>$. Acesso em: 11 mar. 2011. doi: 10.1590/S0100-29452009000100041.

FERREIRA, D.S. et al. Compostos bioativos presentes em amorapreta (Rubus spp.). Revista Brasileira de Fruticultura, v.32, n.3, p.664-674, 2010. Disponível em: <http://www.scielo.br/ scielo.php? script=sci_art text \& pid=S0100- 29452010000300004\&lng=pt\&nrm=iso >. Acesso em: 11 mar. 2011. doi: 10.1590/S0100-29452010005000110.

HALL, H.K.; LANGFORD, G. The 'Boysenberry': development of the cultivar and industries in California, Oregon and New Zealand. Acta Horticulturae, n.777, p.103-108, 2008.

HAN, H. et al. A review on the molecular mechanism of plants rooting modulated by auxin. African Journal of Biotechnology, v.8, n.3, p.348-353, 2009.

LJUNG, K. et al. Sites and homeostatic control of auxin biosynthesis in Arabidopsis during vegetative growth. Plant Journal: for Cell and Molecular Biology, v.28, n.4, p.465474, 2001.

PIO, R. et al. Enraizamento de estacas juvenis do marmeleiro 'Japonês' estratificadas a frio e tratadas com AIB. Ciência e Agrotecnologia, v.31, n.1, p.71-74, 2007. Disponível em: <http://www.scielo.br/scielo.php?script=sci_arttext\&pid=S1413$70542007000100011 \& \operatorname{lng}=p t \& n r m=i s o \& t \operatorname{lng}=p t>$. Acesso em: 11 mar. 2011. doi: 10.1590/S1413-70542007000100011.

SALIBE, A.B. et al. Enraizamento de estacas do porta-enxerto de videira 'VR 043-43' submetidas a estratificação, ácido indolbutírico e ácido bórico. Bragantia, v.69, n.3, p.617-622, 2010. Disponível em: <http://www.scielo.br/ scielo.php? script =sci_arttext \& pid=S000687052010000300013\&lng=pt\&nrm=iso $>$. Acesso em: 29 abr. 2011. doi: 10.1590/S0006-87052010000300013.

VILLA, F. et al. Propagação de amoreira-preta utilizando estacas lenhosas. Ciência e Agrotecnologia, v.27, n.4, p.829-834, 2003. Disponível em: <http://www.scielo.br/ scielo.ph p ? s c ri pt =s ci_art text \& pid = S 1413 $70542003000400013 \& \operatorname{lng}=p t \& n r m=i s o \& t \operatorname{lng}=p t>$. Acesso em: 11 mar. 2011. doi: 10.1590/S1413-70542003000400013. 